\title{
Soft Skill Development in Ophthalmology and its Importance to Aspiring Canadian Medical Students
}

\author{
Carter William Lim¹, Cindy M.L. Hutnik ${ }^{2,3}$ \\ ${ }^{1}$ Faculty of Medicine, University of Ottawa \\ ${ }^{2}$ Department of Ophthalmology, Western University \\ 3/vey Eye Institute, St. Joseph's Hospital
}

\section{ABSTRACT}

Soft skills are social and emotional intelligences that facilitate harmonious interpersonal interactions. Soft skills enable physicians to understand and build rapport with patients. Soft skills are increasingly considered crucial physician qualities within surgical specialties, including ophthalmology. Although avenues exist for general soft skill development, medical students may find challenges directing their development to ophthalmic settings due to medical curricula's limited ophthalmology exposure. This perspective commentary discusses resources to aid ophthalmic soft skill development. Lectures provide foundational knowledge. Electives and volunteering provide opportunities to practice soft skills. Electives and mentorship direct soft skills towards desired disciplines. Studying and participating in research that utilizes patient-centred outcomes improves current and future care.

\section{RÉSUMÉ}

Les compétences relationnelles sont des intelligences sociales et émotionnelles qui facilitent les interactions interpersonnelles harmonieuses. Ces compétences permettent aux médecins de comprendre et d'établir des rapports avec les patients. elles sont de plus en plus considérées comme des qualités médicales essentielles dans les spécialités chirurgicales, y compris en ophtalmologie. Bien qu'il existe des avenues pour le développement général des compétences, les étudiants en médecine peuvent trouver des difficultés à orienter leur développement vers des contextes ophtalmologiques en raison de l'exposition limitée aux programmes d'études en ophtalmologie. Ce commentaire de perspective discute des ressources pour aider au développement de compétences relationnelles ophtalmiques. Les conférences fournissent des connaissances fondamentales. Les cours facultatifs et le bénévolat offrent des occasions de pratiquer des qualités personnelles. Les cours au choix et le mentorat orientent les compétences non techniques vers les disciplines souhaitées. Étudier et participer à des recherches qui utilisent des résultats centrés sur le patient améliore les soins actuels et futurs.

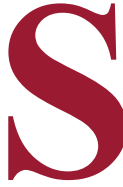
oft skills, also known as non-technical skills, facilitate harmonious interactions between people. These skills include communication, professionalism, adaptability, and interpersonal skills like empathy and conflict resolution $(1,2)$. Soft skills enable us to build trusting relationships with our patients and understand their personal experiences and needs. This understanding can be used to communicate our medical expertise and direct research initiatives to improve future care. Soft skills are included within CanMEDS roles' core competencies (3). As Canadian postgraduate medical education transitions to a competency-based design, it is anticipated that there will be an increased focus on core competency skillset assessment $(4,5)$. Thus, soft skill development will become a greater focus for trainees.

Soft skills are increasingly being considered crucial qualities in surgical specialties, as they improve patient management and teamwork in both clinic and operating room settings $(6,7)$. Ophthalmology utilizes diverse treatment modalities, including surgical, laser, and medical interventions. In ophthalmology, quality of life improvement is most often the objective. While the most feared result of eye disease is sight loss, patients' quality of life is also impacted by psychosocial, emotional, and systemic consequences of the disease and their treatment (8-13). Because quality of life is defined by personal experience, an intimate understanding of patients' perspectives is needed to optimize care $(14,15)$. Consequently, soft skills are highly-desired traits in both comprehensive and subspecialty ophthalmologists (16).

Medical students acquire soft skills longitudinally through collections of personal experiences (Figure 1). Although general soft skills are translatable across specialties, a deeper understanding of specialty-specific situations where soft skills are

Keywords: Soft skill; Non-technical skill; Medical education; Patient-centred care; Ophthalmology 
Lectures

Discussion of patients perspectives

\section{Electives}

- Patient interaction

- Observation and discussion with preceptors who possess and exemplify soft skills.
Community-based Volunteering

- Understand disease-specific

challenges that patients encounter

- Create opportunities for advocacy

Mentor-Mentee Relationship

- Development of soft skills not addressed in formal curriculum
Patient-centred Peer-Reviewed Research

- Understand how patient's voice can be incorporated in research - $\quad$ PROMs

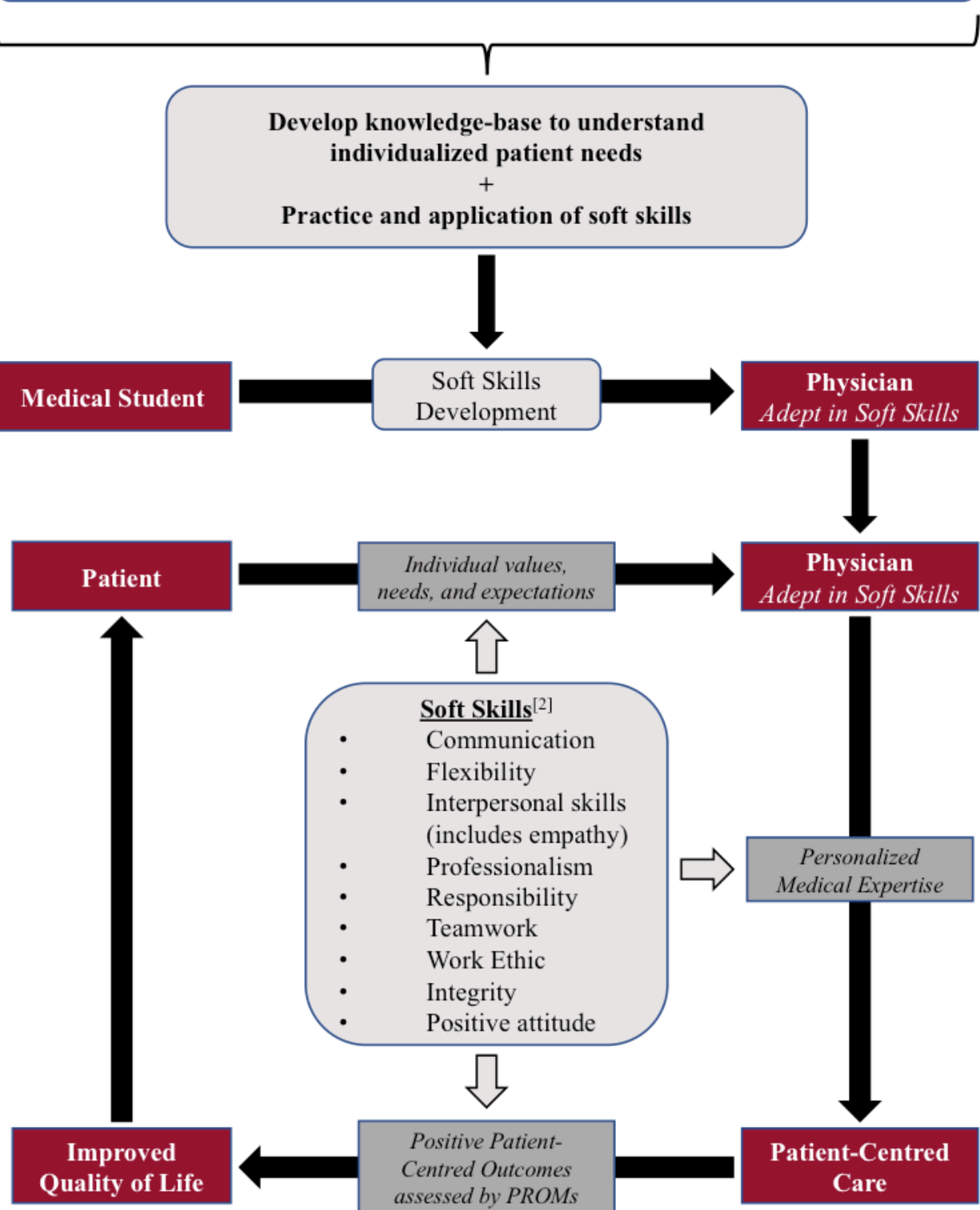

Figure 1. Schematic representation of resources that aid soft skill development in medical students, and how these soft skills can then be applied in routine clinical care. Abbreviations: PROMs, patient-reported outcome measures. 
particularly important enables students to play more significant roles on healthcare teams (6), partake in research with patientcentred outcomes, and develop strong soft skills foundations before entering residency. Due to the limited ophthalmology exposure in undergraduate medical curricula, medical students may find particular challenges in directing their soft skills development in an ophthalmic setting.

In this commentary, the focus will be on the learning experiences from a medical student's perspective. Through anecdotal discussion and literature review, the aim will be to convey the importance of soft skills, discuss how medical students can actively improve soft skill development, and direct this development to ophthalmology.

What soft skill development resources are available for students?

Soft skill development can be attained through several facets within medical education, including lectures, electives, research, and community-based volunteering.

\section{LECTURES}

Canadian undergraduate medical education programs have made recent changes to help students understand individualized perspectives of patients and their communities (17). These aspects of curricula improve soft skill development foundations by familiarizing students with specific populations' needs and available patient resources (17). Specifically, the University of Ottawa's medical program has Society, Individual, and Medicine (SIM) classes where patients, physicians, and allied health professionals discuss social determinants of health, diseases' impacts on quality of life, and specific healthcare needs of vulnerable patient populations (18-20). Students also have access to a supplemental SIM website that builds around the foundational knowledge developed in class (18).

During SIM, there is discussion of the importance of exploring patients' concerns beyond their presenting complaints, as patients often have several related, co-existing problems just beneath the surface that will affect care of the current illness (21). For physicians to engage in patient-centred care, tme must be taken to understand patients' lives as a whole rather than a compilation of current symptoms and signs (21). By understanding these concepts learned in SIM, students develop a foundational approach to build empathy for their patients, thereby aiding in the establishment of therapeutic alliances.

\section{ELECTIVES AND OBSERVERSHIPS}

Electives and observerships provide students with opportunities to practice soft skills by participating in patient care and learning from preceptors who already possess these skills. During electives, students can form mentor-mentee relationships with physicians they particularly respect, identify with, and admire. Mentors aid in soft and clinical skills development that are not addressed in formal undergraduate curricula (22). Mentors achieve this by acting as coaches to help students set career goals, improve resilience, provide feedback, and develop important insight for being successful physicians (23).

For example, ICU electives provide students opportunities to learn from physicians who are often particularly adept at soft skills. During these electives, students may apply lessons from SIM, such as the intricacies of autonomy, medical beneficence, and substitute decision making (24). This knowledge helps students initiate soft skill-related discussions with their ICU mentors, who can then help students develop their approach to soft skill-critical scenarios, such as the resolution of ethical conflict to deliver optimal patient-centred care. End-of-life care exemplifies complexities that coincide with patient-centred care. Here, physicians must elucidate patients' values and goals of care while patients often have minimal capacity to communicate new information or appreciate the consequences of various actions. In addition, physicians must effectively communicate with patients' families. Although knowing this information is essential, its utility depends on the physician's soft skills.

Patient-centred care often involves balancing patients' autonomy and beneficence when conflict exists between these two ethical principles (25). In paternalistic care, physicians are the dominant authority and decision maker in patient treatment $(26,27)$. Although most of medicine is shifting away from traditional paternalistic care (28), patient-centred care is not necessarily the complete antithesis to that of paternalism (26). Patient-centred care is not simply fulfilling a patient's every request. Rather, a physician's responsibility is to understand their patient's values and provide guidance that best meets their goals. Otherwise, we are abandoning them to their autonomy.

Execution of successful patient-centred guidance requires effective listening, understanding values, and establishing trusting relationships. To fulfill these requirements, physicians must 
create non-judgmental environments and orchestrate discussion with empathy, respect, and authenticity. Without soft skills, a physician cannot possibly provide medical expertise that the patient needs and therefore cannot provide the high-quality patient-centred care that they deserve. With these soft skills, we build trust with our patients - bridging the gap between our medical knowledge and the patient's care. This connection allows us to approach medicine in a patient-centred fashion.

\section{TRANSLATION OF SOFT SKILLSTO A DISEASE-SPECIFIC FOCUS} Glaucoma, a leading cause of irreversible blindness worldwide (29), is characterized by progressive optic neuropathy, initially manifesting as peripheral vision loss (30). As such, patients may not notice reductions in their visual field until significant permanent vision loss has already occurred. In the current glaucoma treatment paradigm, intraocular pressure-reducing topical medications are considered first-line therapy (30). Because glaucoma is a chronic disease with currently no known cure, medical therapy must also be chronic and life-long. Consequently, medication adherence is crucial for successful management. Similar to the previously described ICU example, glaucoma medication non-adherence may present conflicts between a patient's autonomy and beneficence.

Schwartz and Quigley's (2008) literature review found that adherence to glaucoma medications was generally below $50 \%$ after one year of therapy (31). The question arises as to the possible role soft skills play in reducing non-compliance. Many commonly reported barriers to glaucoma medication adherence - poor self-efficacy $(32,33)$, patients' skepticism that glaucoma causes vision loss (33-35), skepticism regarding the effectiveness of glaucoma medications (32-37), poor glaucoma knowledge (33-38), mistrust in physician (33,36-38) - are directly affected by the patient-physician relationship. Other commonly reported barriers - forgetfulness $(33,35-37,39)$, administration difficulties $(32,33,35,37,39)$, cost $(33,34,37,39)$, adverse effects of medication $(33,34,37,39)$, and perceived stress, depression, or anxiety $(9,13,40)$ - should be amenable to elucidation by physicians with a thorough patient history.

Physicians' soft skills create opportunities to facilitate open, candid, and non-judgmental dialogue with patients, allowing physicians to engage in discussions with their patients regarding their beliefs on their disease and its treatment (33). Physicians can address these beliefs to improve self-efficacy through motivational counselling and individualized education, and provide personalized techniques to help patients with their forgetfulness $(33,41)$. By addressing psychosocial issues such as mental health or financial concerns, we can identify patients that require referral to appropriate members of our healthcare team $(13,42)$. If compliance remains challenging due to numerous adherence barriers, then physicians can consider alternative therapies that reduce the patient's active involvement such as - in the case of glaucoma management - laser-based therapies.

By integrating knowledge and soft skills acquired from lectures and electives, students can direct their development towards an ophthalmic focus. For example, lessons learned during SIM classes and ICU electives regarding the importance of exploring patients' concerns through effective communication and empathy can motivate a student to inquire further about patients' glaucoma medication adherence. By understanding patients' needs, we can provide the medical expertise that we have spent so many years acquiring for the benefit of our patients. Rather than abandoning patients to their autonomy, we can work cohesively with them as a team to provide optimal patient-care.

\section{RESEARCH}

In ophthalmology, traditional clinical outcome measures (COMs) - like visual acuity and intraocular pressure - do not always correlate with patient-reported outcome measures (PROMs) - such as functionality during sight-dependent daily activities like driving or reading (43). Both clinical research and routine clinical practice are increasingly using PROMs, as they capture patients' experiences better than COMs (43). Eye care providers must understand how patients value sight and their expectations of care. These may be patient-specific, which would cause a general, empirical approach to be suboptimal. Validated PROM questionnaires allow us to better understand ophthalmic outcomes from patients' perspectives (43). By familiarizing themselves with this research, students develop a sense of where their soft skills are particularly needed within ophthalmology.

For example; in cataract surgery, patients' expectations of outcomes are high (44). Although patient satisfaction is generally concomitantly high, this is not always the case $(45,46)$. Using the Catquest-9SF PROM questionnaire, Mollazadegan and Lundström (2015) found that although PROMs were generally good, poor PROMs were associated with higher preoperative 
visual function (47). Moreover, $7.4 \%$ of patients demonstrated improved visual acuity but poor PROMs (47). This discrepancy was associated with difficulties performing near-vision tasks after surgery (47). Nuclear cataracts, which at their onset temporarily improve near-vision, may negatively impact patients' perceived outcomes if not correctly informed (47). Thus, preoperative identification and discussion of pre-existing factors may improve surgical outcomes as assessed by PROMs.

As members of the ophthalmic care team, medical students may be approached by patients or otherwise become involved in pre-operative cataract surgery care. By understanding how a patient's COMs and PROMs may differ, students recognize the importance of inquiring about their patient's specific limitations from their cataract. By understanding how patients typically value outcomes in cataract surgery, students become aware of pre-existing factors that should be addressed. This awareness directs soft skill development to this specific ophthalmologic situation. The student is better equipped to explore patients' expectations and underlying concerns. Students can then engage their preceptors in discussions on how to improve quality of care by providing the specific information their patient needs.

In addition, students' appreciation of the importance of PROMs may help them participate in progressive research with robust, patient-centred methodologies. Participation in patientcentred ophthalmic research may be achieved by contacting potential supervisors and engaging in discussion of patientcentred outcomes within projects. This active dialogue alerts the researcher of their student's focus, which may expand the student's role on the team, allow students to direct their own initiatives, and help students meet their academic and professional goals.

\section{VOLUNTEERING}

Volunteering with organizations that provide services to citizens with visual impairments is another great approach for building soft skills. The Vision Mate program at the Canadian National Institute for the Blind (CNIB) pairs students with clients who request assistance to complete specific tasks (48). In the Vision Mate program, students witness the abundant accessibility issues that people with visual disabilities experience, and the challenges of performing daily activities like navigating websites, transportation, or career-related tasks. Students who witness these accessibility problems gain understanding of specific obstacles to which they can advocate. Volunteers will understand how those with visual impairments adapt their learning style or techniques when performing certain tasks. This understanding helps students become mindful and accommodating of people with visual impairments by adapting their own teaching or performance techniques. Students will grow to admire their client's determination in achieving their objectives despite experiencing numerous additional obstacles that most others do not encounter. As a team, students will find satisfaction working through adversity with their client. Students will become aware of valuable resources that provide assistance to those with low vision. As medical students progress through their professional careers, the knowledge, adaptability, empathy, and sense of responsibility acquired from community-based volunteering can be applied to their future practice or advocacy initiatives.

\section{CONCLUSIONS}

Soft skill training and development have been historically absent in medical training. Their need and value have only recently become of greater interest. Growing evidence suggests that soft skills are equally as important and foundational as knowledge and technical skills. Research supports that soft skill development should start early in physicians' careers as it is neither intuitive nor inherent in all students selected to become physicians. Medical students have many opportunities to actively direct their soft skill development (Figure 1). Lectures, electives, and volunteering provide the foundation to develop and practice soft skills. Electives and mentorship direct these skills towards desired disciplines. Studying and participating in research with patient-centred outcomes enables students to take initiative in improving current and future care. We encourage all students to realize the positive influence and role they can have by actively integrating soft skills into their education, which in turn can translate into a very rewarding career in medicine.

\section{ACKNOWLEDGMENTS}

Dr. Andrew Seely, MD; Department of Surgery, The Ottawa Hospital - General Campus

\section{REFERENCES}

1. Weiszbrod T. Health care leader competencies and the relevance of emotional intelligence. Health Care Manag (Frederick). 2015 Jun;34(2):140-6.

2. Robles MM. Executive Perceptions of the Top 10 Soft Skills Needed in Today's Workplace. Business Communication Quarterly. 2012 Oct;75(4):45365.

3. CanMEDS: Better standards, better physicians, better care [Internet]. The 
Royal College of Physicians and Surgeons of Canada: CanMEDS Framework. [cited 2017 Dec 25]. Available from: http://www.royalcollege.ca/rcsite/canmeds/canmeds-framework-e

4. Ten Cate O. Competency-Based Postgraduate Medical Education: Past, Present and Future. GMS J Med Educ. 2017 Feb;34(5):69.

5. Schultz K, Griffiths J. Implementing Competency-Based Medical Education in a Postgraduate Family Medicine Residency Training Program: A Stepwise Approach, Facilitating Factors, and Processes or Steps That Would Have Been Helpful. Acad Med. 2016 May;91(5):685-9.

6. Farmer DL. Soft Skills Matter. JAMA Surg. 2015 Mar 1;150(3):207.

7. Agha RA, Fowler AJ, Sevdalis N. The role of non-technical skills in surgery. Ann Med Surg (Lond). 2015 Oct 9;4(4):422-7.

8. Boyle J, Vukicevic M, Koklanis K, Itsiopoulos C, Rees G. Experiences of patients undergoing repeated intravitreal anti-vascular endothelial growth factor injections for neovascular age-related macular degeneration. Psychol Health Med. 2018 Feb;23(2):127-40.

9. Arora V, Bali SJ, Gupta SK, Vashisht P, Agarwal T, Sreenivas V, et al. Impact of initial topical medical therapy on short-term quality of life in newly diagnosed patients with primary glaucoma. Indian J Ophthalmol. 2015 Jun;63(6):511-5.

10. Meyer-Ruesenberg B, Richard G. [New insights into the underestimated impairment of quality of life in age-related macular degeneration - a review of the literature]. Klin Monbl Augenheilkd. 2010 Aug;227(8):646-52.

11. Chang MY, Velez FG, Demer JL, Isenberg SJ, Coleman AL, Pineles SL. Quality of life in adults with strabismus. Am J Ophthalmol. 2015 Mar;159(3):539-44. e2.

12. Lehane CM, Dammeyer J, Elsass P. Sensory loss and its consequences for couples' psychosocial and relational wellbeing: an integrative review. $\mathrm{Ag}$ ing Ment Health. 2017 Apr;21(4):337-47.

13. Méndez-Ulrich JL, Sanz A. Psycho-ophthalmology: Contributions of Health psychology to the assessment and treatment of glaucoma. Psychol Health. 2017 Mar;32(3):330-42.

14. Harkness J. Patient involvement: a vital principle for patient-centred health care. World Hosp Health Serv. 2005;41(2):12-6, 40-3.

15. Huffman MH. Health Coaching: a fresh, new approach to improve quality outcomes and compliance for patients with chronic conditions. Home Healthc Nurse. 2009 Sep;27(8):490-6.

16. Michels KS, Hansel TEB, Choi D, Lauer AK. A survey of desired skills to acquire in ophthalmology training: a descriptive statistical analysis. Ophthalmic Surg Lasers Imaging. 2007 Apr;38(2):107-14.

17. FMEC MD 2015: Five Years of Innovations at Canadian Medical Schools [Internet]. Ottawa, Ontario: The Association of Faculties of Medicine of Canada (AFMC); 2015 Jan [cited 2018 Mar 27]. (The Future of Medical Education in Canada (FMEC): A Collective Vision for MD Education 2010-2015). Available from: https://afmc.ca/pdf/fmec/FMEC-MD-2015.pdf

18. The SIM Website [Internet]. Society, Individual, and Medicine. [cited 2017 Dec 27]. Available from: https://www.med.uottawa.ca/sim/welcome_e. html

19. Davies BL, Bertrand J, Douek DJ. Transgender Issues: Trans Health Perspectives. PowerPoint presented at: Society, Individual, and Medicine Class; 2017 Nov 9; University of Ottawa.

20. Kilabuk E. Inuit pulmonary health, history, geography, and social determinants of health. PowerPoint presented at: Society, Individual, and Medicine Class; 2017 Mar 7; University of Ottawa.

21. Jones G. Social Determinants of Health. PowerPoint presented at: Society, Individual, and Medicine Class; 2016 Sep 12; University of Ottawa.

22. Nassrallah G, Arora S, Kulkarni S, Hutnik CML. Perspective on a formal mentorship program in ophthalmology residency. Can J Ophthalmol. 2017 Aug;52(4):321-2.

23. Lovell B. What do we know about coaching in medical education? A literature review. Med Educ. 2017 Dec 11;52(4):376-90.

24. Williams JR. End-Of-Life Care. PowerPoint presented at: Society, Individual, and Medicine Class; 2017 Feb 21; University of Ottawa.

25. Hébert PC. Doing right: a practical guide to ethics for medical trainees and physicians. Third edition. Don Mills, Ontario: Oxford University Press; 2014.
26. Komrad MS. A defence of medical paternalism: maximising patients' autonomy. J Med Ethics. 1983 Mar;9(1):38-44.

27. Sandman L, Munthe $C$. Shared decision making, paternalism and patient choice. Health Care Anal. 2010 Mar;18(1):60-84.

28. Chin JJ. Doctor-patient relationship: from medical paternalism to enhanced autonomy. Singapore Med J. 2002 Mar;43(3):152-5.

29. Quigley HA. The number of people with glaucoma worldwide in 2010 and 2020. British Journal of Ophthalmology. 2006 Mar 1;90(3):262-7.

30. National Eye Institute (NIH). Facts About Glaucoma [Internet]. National Eye Institute (NIH). 2015 [cited 2018 Mar 27]. Available from: https://nei. nih.gov/health/glaucoma/glaucoma_facts

31. Schwartz GF, Quigley HA. Adherence and persistence with glaucoma therapy. Surv Ophthalmol. 2008 Nov;53 Suppl1:S57-68.

32. Sleath B, Blalock SJ, Robin A, Hartnett ME, Covert D, DeVellis B, et al. Development of an instrument to measure glaucoma medication self-efficacy and outcome expectations. Eye (Lond). 2010 Apr;24(4):624-31.

33. Newman-Casey PA, Robin AL, Blachley T, Farris K, Heisler M, Resnicow K, et al. The Most Common Barriers to Glaucoma Medication Adherence: A Cross-Sectional Survey. Ophthalmology. 2015 Jul;122(7):1308-16.

34. Friedman DS, Hahn SR, Gelb L, Tan J, Shah SN, Kim EE, et al. Doctor-patient communication, health-related beliefs, and adherence in glaucoma results from the Glaucoma Adherence and Persistency Study. Ophthalmology. 2008 Aug;115(8):1320-7, 1327.e1-3.

35. Lacey J, Cate H, Broadway DC. Barriers to adherence with glaucoma medications: a qualitative research study. Eye (Lond). 2009 Apr;23(4):924-32.

36. Stryker JE, Beck AD, Primo SA, Echt KV, Bundy L, Pretorius GC, et al. An exploratory study of factors influencing glaucoma treatment adherence. J Glaucoma. 2010 Jan;19(1):66-72.

37. Tsai JC, McClure CA, Ramos SE, Schlundt DG, Pichert JW. Compliance barriers in glaucoma: a systematic classification. J Glaucoma. 2003 Oct;12(5):393-8.

38. Lunnela J, Kääriäinen $M$, Kyngäs $H$. The views of compliant glaucoma patients on counselling and social support. Scand J Caring Sci. 2010 Sep;24(3):490-8.

39. Taylor SA, Galbraith SM, Mills RP. Causes of non-compliance with drug regimens in glaucoma patients: a qualitative study. J Ocul Pharmacol Ther. 2002 Oct; 18(5):401-9.

40. Sleath BL, Blalock SJ, Muir KW, Carpenter DM, Lawrence SD, Giangiacomo $\mathrm{AL}$, et al. Determinants of Self-Reported Barriers to Glaucoma Medicine Administration and Adherence: A Multisite Study. Ann Pharmacother. 2014 Jul;48(7):856-62.

41. Joseph A, Pasquale LR. Attributes Associated with Adherence to Glaucoma Medical Therapy and its Effects on Glaucoma Outcomes: An EvidenceBased Review and Potential Strategies to Improve Adherence. Semin Ophthalmol. 2017 Oct;32(1):86-90.

42. Slota C, Davis SA, Blalock SJ, Carpenter DM, Muir KW, Robin AL, et al. Patient-Physician Communication on Medication Cost during Glaucoma Visits. Optom Vis Sci. 2017 Dec;94(12):1095-101.

43. Dean S, Mathers JM, Calvert M, Kyte DG, Conroy D, Folkard A, et al. "The patient is speaking": discovering the patient voice in ophthalmology. British Journal of Ophthalmology. 2017 Jun 1;101(6):700-8.

44. Pager CK. Expectations and outcomes in cataract surgery: a prospective test of 2 models of satisfaction. Arch Ophthalmol. 2004 Dec;122(12):178892.

45. Kirwan C, Nolan JM, Stack J, Moore TCB, Beatty S. Determinants of patient satisfaction and function related to vision following cataract surgery in eyes with no visually consequential ocular co-morbidity. Graefes Arch Clin Exp Ophthalmol. 2015 Oct;253(10):1735-44.

46. Addisu Z, Solomon B. Patients' Preoperative Expectation and Outcome of Cataract Surgery at Jimma University Specialized Hospital -Department of Ophthalmology. Ethiop J Health Sci. 2011 Mar;21(1):47-55.

47. Mollazadegan K, Lundström M. A study of the correlation between patient-reported outcomes and clinical outcomes after cataract surgery in ophthalmic clinics. Acta Ophthalmol. 2015 May 1;93(3):293-8.

48. Volunteer Your Tme [Internet]. Canadian National Institute of Blindness (CNIB). [cited 2017 Dec 27]. Available from: http://www.cnib.ca/en/getinvolved/volunteer-your-tme/Pages/default.aspx 